\title{
Avulsion fractures of the proximal tibial epiphysis
}

\author{
G. Inoue $M D^{1}, K$ Kuboyama $M D^{2}$ and T. Shido $M D^{3}$ \\ ${ }^{1}$ Department of Orthopaedic Surgery, Branch Hospital, Nagoya University School of Medicine, Nagoya, Japan \\ ${ }^{2}$ Kuboyama Orthopaedic Clinic, Shizuoka, Japan \\ ${ }^{3}$ Department of Orthopaedic Surgery, Hamamatsu Medical Centre, Hamamatsu, Japan
}

\begin{abstract}
Fractures of the tibia through the proximal epiphysis are rare. This injury usually results from severe direct or indirect force about the knee, and has not been described as resulting from a patellar tendon avulsion injury. Four patients presented with five avulsion fractures of the proximal tibial epiphysis. All were older adolescent males who had been engaged in jumping sports when the injury occurred; one had bilateral injury. All the patients were treated by closed reduction and plaster cast immobilization for 4-8 weeks, with satisfactory results. On the basis of our cases and five cases previously reported, the authors would agree with Ryu and Debenham's suggestion that the Watson-Jones classification, which divides avulsion fractures of the tibial tubercle into three types, should be expanded to include this fourth type - avulsion fracture of the proximal tibial epiphysis.
\end{abstract}

Keywords: Avulsion fracture, tibia, epiphysis, jumping sports

Fractures of the proximal tibial epiphysis are rare adolescent injuries which are produced by two different mechanisms: severe direct or indirect force about the knee separating the tibia through the full width of the proximal tibial epiphysis or an avulsion force separating the anterior portion of the proximal tibial epiphysis. The former is usually caused by a high-energy motor accident or collision during a contact sport, while the latter is caused by a high-tensile load to the tibial tuberosity during a jumping sport. A total fracture-separation of the proximal tibial epiphysis caused by an avulsion force is extremely rare. The authors have found only five fractures reported in the literature ${ }^{1-3}$.

In the present report, five such fractures are described in four patients who were injured in jumping sports.

\section{Material and methods}

Table 1 summarizes the clinical information on these patients. All were boys, two aged 15 years and two aged 16. Three patients showed unilateral involvement and one bilaterial involvement, and all fractures were closed. All of the injuries were sustained during

Address for correspondence: G. Inoue MD, Department of Orthopaedic Surgery, Branch Hospital, Nagoya University School of Medicine, 1-1-20 Daikominami, Higashi-ku, Nagoya 461, Japan

(C) 1991 Butterworth-Heinemann Ltd.

0306-3674/91/010052-05 sporting activities: two boys were injured during a high jump, one in a long jump, and one during basketball. In three of the five fractures, the patients felt that their injuries occurred on take-off for their jump while the remaining two injuries occurred on landing. All patients presented with pain and swelling about the anteromedial part of the proximal end of the tibia. Three patients were unable to extend the involved knee or bear weight.

Radiographs revealed a Salter-Harris type II fracture of the proximal tibial epiphysis ${ }^{4}$ : this was an avulsion fracture of the tibial tuberosity with the fracture line extending through the proximal tibial physis and metaphysis into the posterior cortex. Displacement of the fragment with posterior angulation was noted in four fractures: these were treated by closed reduction and long-leg cast immobilization for 4-8 weeks. One of these injuries required percutaneous pinning to stabilize the fracture. One fracture, where there was no displacement of the fragment, was treated in a cylinder cast for 4 weeks. An undisplaced fibular fracture at the same level as the tibial fracture was recognized in two patients. No neurovascular damage was noted in our series.

\section{Results}

In all patients the fractures healed uneventfully and full weight-bearing was allowed after 4-8 weeks. The patients were able to return to full activity after approximately 3 months. They had a minimum follow-up of 1 year, with a mean follow-up of 15 months. All patients had a full range of knee movement and normal quadriceps function with no muscle atrophy. Although premature closure of the involved tibial physis was recognized in two patients, there was no discrepancy in length or angular deformity of the legs.

\section{Case reports}

Case 1 A 16-year-old boy, experienced sudden right knee pain with 'a pop' when he took-off for a long jump off his right leg. He landed with both knees flexed. The patient noted severe pain in both knees and was unable to stand up. Examination revealed gross swelling and tenderness along the anteromedial proximal metaphysis. The patient was unable to extend either leg. He had a history of clinically asymptomatic Osgood-Schlatter disease of both knee joints. 
Avulsion fractures of the proximal tibial epiphysis: M. D. Inoue et al.

Table 1. Summary of cases

\begin{tabular}{|c|c|c|c|c|c|c|}
\hline Case no. & $\begin{array}{l}\text { Involved } \\
\quad \operatorname{limb}\end{array}$ & $\begin{array}{l}\text { Age at } \\
\text { Injury } \\
\text { (years) }\end{array}$ & $\begin{array}{l}\text { Mechanism } \\
\text { of injury }\end{array}$ & Treatment & $\begin{array}{l}\text { Follow-up } \\
\text { (months) }\end{array}$ & Remarks \\
\hline \multirow[t]{2}{*}{1} & $\mathbf{R}$ & 16 & $\begin{array}{l}\text { Long jump } \\
\text { (take-off) }\end{array}$ & Cast & 12 & PCP \\
\hline & L & 16 & $\begin{array}{l}\text { Long jump } \\
\text { (landing) }\end{array}$ & Cast & 12 & $\begin{array}{c}\text { PCP } \\
\text { Fibular fracture }\end{array}$ \\
\hline 2 & $\mathrm{~L}$ & 16 & $\begin{array}{l}\text { High jump } \\
\text { (take-off) }\end{array}$ & Cast & 16 & \\
\hline 3 & $\mathbf{R}$ & 15 & $\begin{array}{l}\text { High jump } \\
\text { (take-off) }\end{array}$ & Cast & 12 & Fibular fracture \\
\hline 4 & L & 15 & $\begin{array}{l}\text { Basketball } \\
\text { (landing) }\end{array}$ & $\begin{array}{c}\text { Cast } \\
\text { Percutaneous pinning }\end{array}$ & 36 & PCP \\
\hline
\end{tabular}

$L$, left; PCP, premature closure of the physis; $R$, right

Radiographs showed a Salter-Harris type II fracture in both legs in an anteroposterior plane through the proximal tibial physis and metaphysis, with posterior angulation (Figure 1). There was also a fibular fracture in the left leg. The fractures were reduced by a closed manipulation with the knee extended and direct manual pressure over the tibial tubercle. Both knees were immobilized in long-leg casts for 6 weeks. Follow-up examination 1 year later revealed no bony abnormality and full range of movement in both knee joints, although radiographs showed premature closure of both tibial physes (Figure 2).

Case 2 A 16-year-old boy sustained injury to the left knee while doing the high jump. He felt that his injury occurred on take-off. At examination he had pain and swelling over the tibial tuberosity. He was able to extend his knee against gravity.

Radiographs revealed that the tongue-like projection of the anterior tibial epiphysis was lifted upward and a fracture line extended obliquely downward across the metaphysis into the posterior cortex (Figure 3 ). The limb was immobilized in a cylinder cast for 4 weeks, and then full weight-bearing was allowed with progression to full activity. One year after injury, he had full range of movement in the knee, no length discrepancy, and no complaints. Radiographs showed no abnormality in the knee.

\section{Discussion}

Fracture of the proximal tibial epiphysis is a rare injury, accounting for between $0.5 \%$ reported by

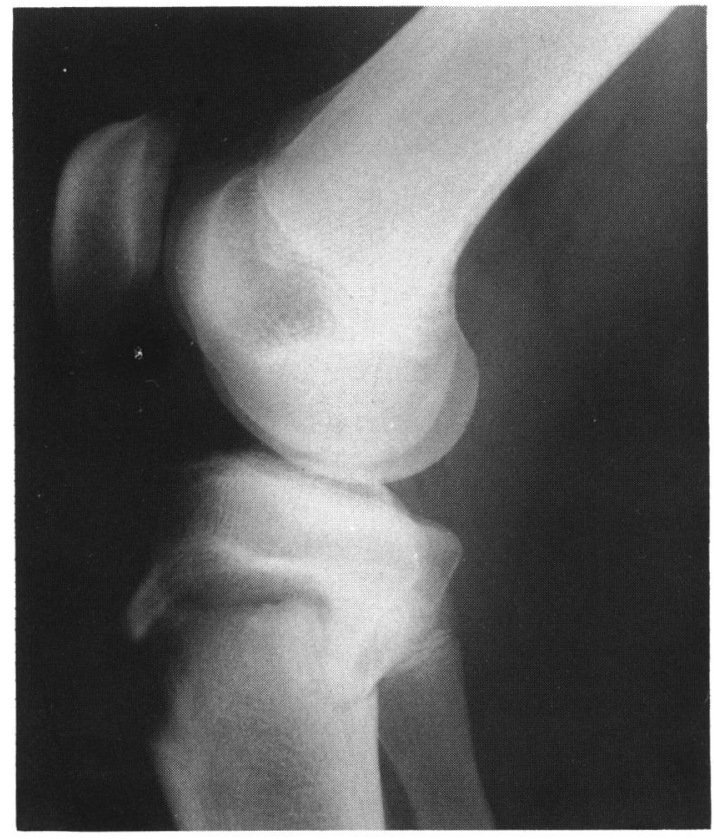

a

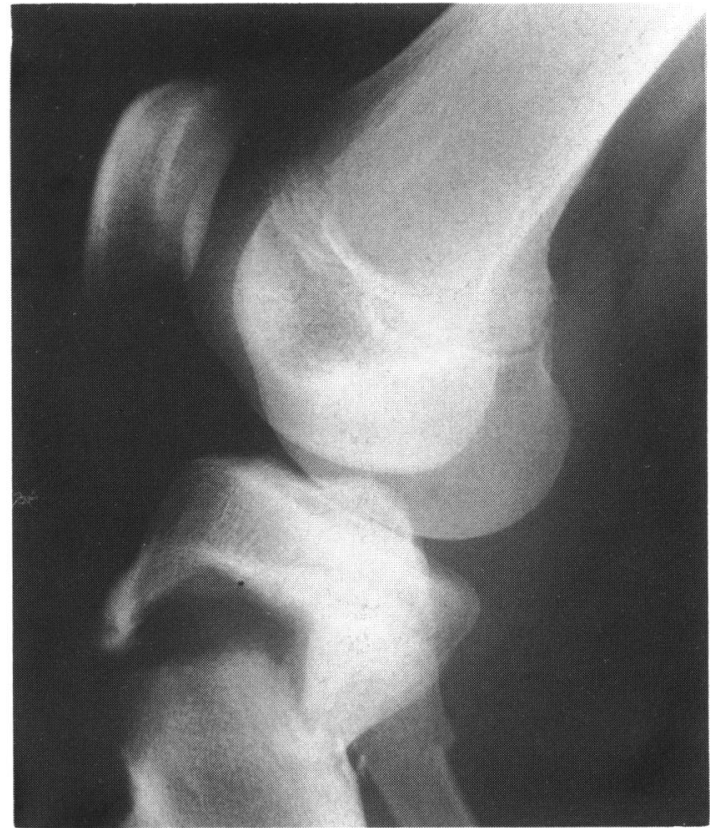

Figure 1. Case 1 a Initial lateral radiograph of the right knee showing an avulsion fracture of the tibial tubercle with a Salter-Harris type II fracture of the proximal epiphysis. b Initial lateral radiograph of the left knee showing a similar findings to that of the right knee. Note a greenstick fracture of the fibula 


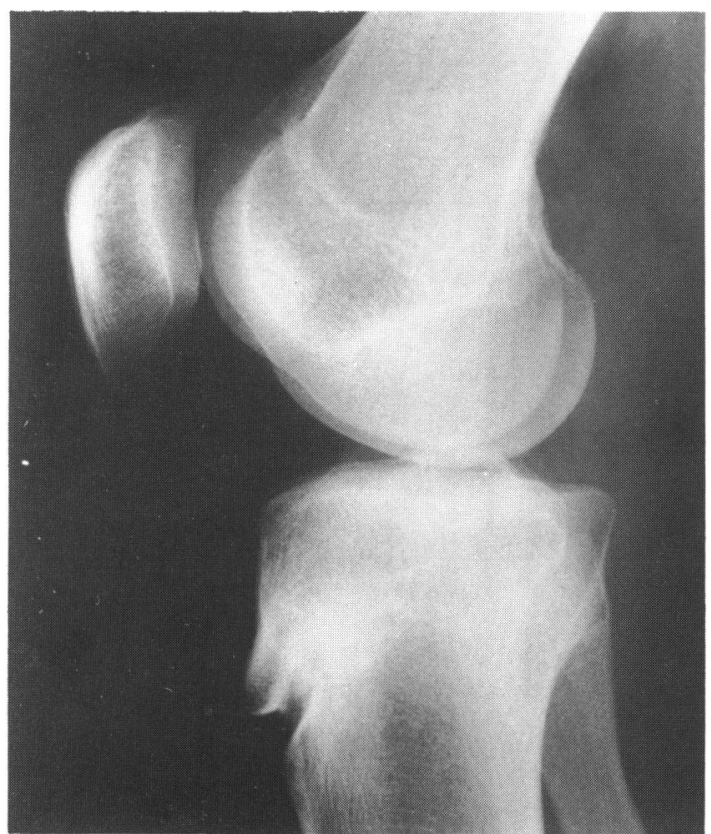

a

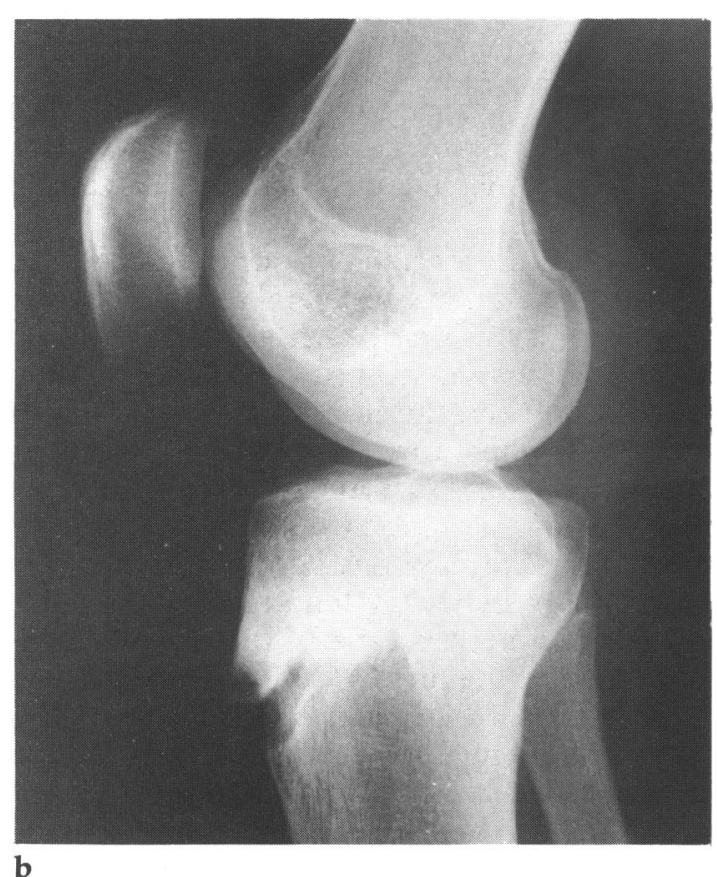

Figure 2. Case 1 Lateral radiographs of both knees (a, right; b, left) 1 year after injury showing premature closure of the tibial physes. There is no deformity

Peterson and Peterson ${ }^{5}$ and $3.06 \%$ reported by Shelton and Canale ${ }^{6}$ of all epiphyseal injuries. This injury can occur from direct or indirect force. A direct injury usually occurs in high-energy motor vehicle accidents while indirect injury can occur from passive hyperextension, abduction or adduction of the legs during sports activities or falls. These injuries are readily typified into Salter-Harris classifications ${ }^{4}$.

An avulsion force usually separates the anterior portion of the proximal tibial epiphysis (tibial tubercle). Watson-Jones ${ }^{7}$ described three types of avulsion fractures of the tibial tubercle (Figure 4). In the first type, a small fragment representing part of

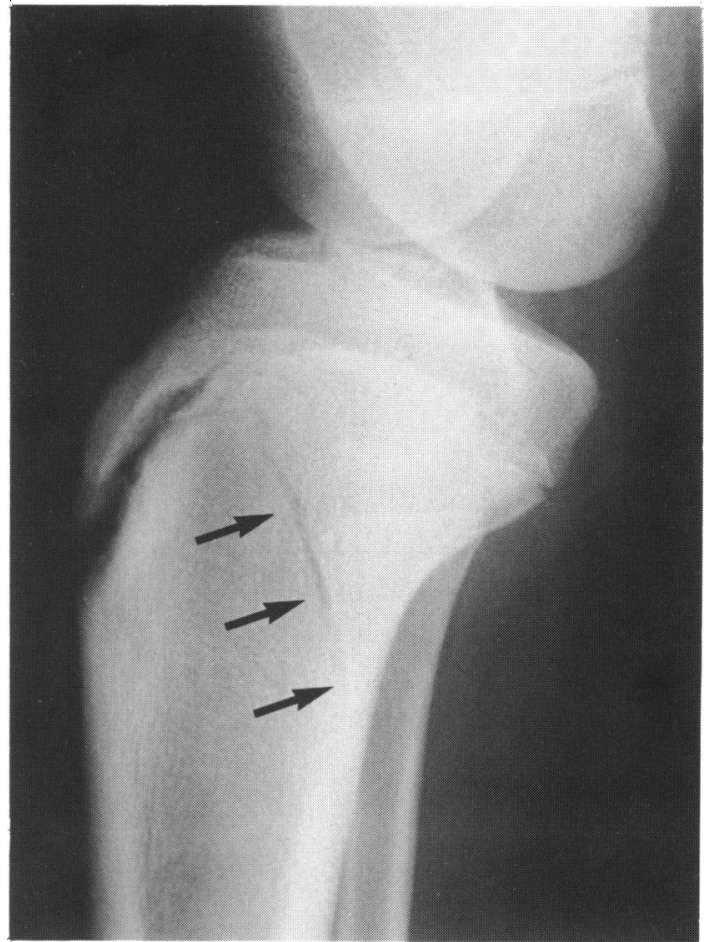

Figure 3. Case 2 Initial lateral radiograph demonstrates that the entire tongue formed by the anterior tibial epiphysis is hinged upward, and a fracture line passes obliquely downward across the metaphysis (arrows)

the tubercle is avulsed and displaced upward. In the second type, the secondary centre of ossification in the tubercle has already coalesced with the remainder of the proximal epiphysis and the entire tongue formed by the tibial tuberosity on the epiphysis is hinged upward. In the third type, the line of fracture passes upward and backward across the proximal articular surface of the tibia. Burkhart and Peterson ${ }^{8}$, and Shelton and Canale ${ }^{6}$ include Watson-Jones type III fracture in their reviews of proximal tibial epiphyseal fractures. However, avulsion fractures of the tibial tubercle seem to constitute a specific subgroup that may be considered to be a separate group.

The avulsion type of fracture of the proximal tibial epiphysis is extremely rare, especially those fractures which start at the tibial tubercle and extend up into the proximal tibial epiphysis, separating both structures. We found only five cases cited in the literature surveyed. Silberman and Murphy ${ }^{1}$ described a Salter-Harris type I fracture of the proximal tibial epiphysis in a 12-year-old boy who sustained right knee injury after 'pushing off' in a high jump. Ryu and Debenham ${ }^{3}$ reported a Salter-Harris type II fracture of the proximal tibial epiphysis that occurred when a 16-year-old boy jumped for a basketball; they proposed that the Watson-Jones classification should be expanded to include as type IV an avulsion fracture of the proximal tibial tubercle which represents a continuation of the fracture forces into the posterior cortex (Figure 5). Usui et al. ${ }^{2}$ described three cases of Salter-Harris type II fractures of the proximal tibial epiphysis in older boys from 15 to 18 years of 


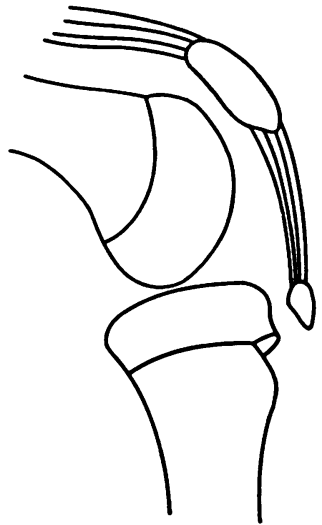

I

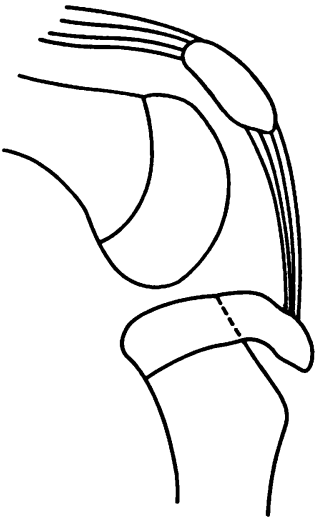

II

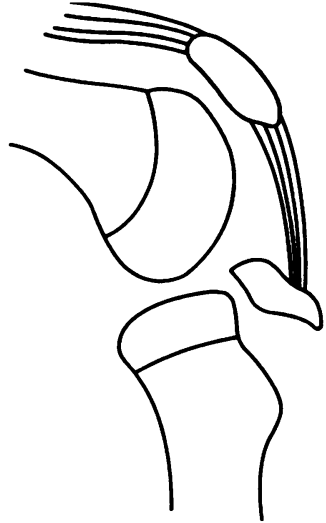

III

Figure 4. Watson-Jones' classification of tibial tubercle fractures. (Reprinted with permission from Wilson JN, Watson-Jones Fractures and Joint Injuries, 5th edn. Edinburgh: Churchill Livingstone, 1976: 1047-50)

age, injured during sporting activities. On the basis of our cases and these five cases previously reported, we would agree with Ryu and Debenham's suggestion that a Watson-Jones classification should be expanded to include this unusual avulsion fracture of the proximal tibial epiphysis as type IV.

Avulsion fractures of the tibial tubercle occur most often during sporting activities. Of the 15 injuries reported by Levi and Coleman", five occurred while playing basketball, two while diving from a springboard, two during competitive running, and one during a high jump. Christie and Dvonch ${ }^{10}$ reported that all eight of their cases occurred while playing basketball. This injury can occur in either of two ways. The first mechanism is violent contraction of the quadriceps muscle against a fixed tibia: it can occur when an athlete takes-off during the jump. The second mechanism is acute passive flexion of the knee against the resistance of a strongly contracting quadriceps muscle: this can occur when an athlete makes a landing at the end of a jump. Levi and Coleman ${ }^{9}$ described five cases that occurred as a
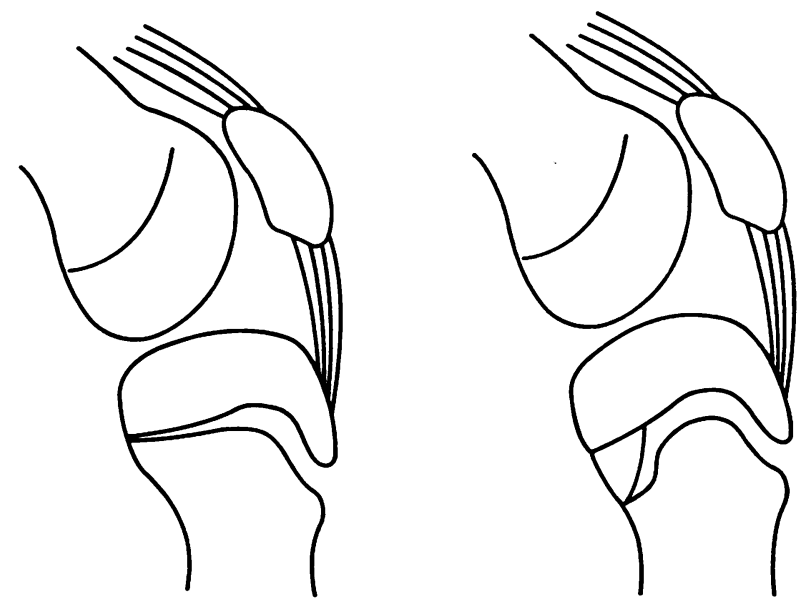

Figure 5. Proposed type IV injury as an addition to the Watson-Jones classification. (Reprinted with permission from Ryu RK. Clin Orthop 1985; 194: 181-4) result of the jump up, five as a result of the landing, while five showed no identifiable mechanisms. Of our four cases with five avulsion fractures of the proximal tibial epiphysis, three occurred during take-off and two during landing. One case with this fracture reported by Silberman and Murphy ${ }^{1}$ and one case reported by Ryu and Debenham ${ }^{3}$ occurred while jumping.

It is interesting that one of our cases (case 1), who sustained simultaneous bilateral avulsion fractures of the proximal tibial epiphysis, suffered injury to his right leg from the initial spring-off to a long jump and to his left leg from landing at the end of the jump. There were only three reports of simultaneous bilateral avulsion fracture of the tibial tubercle. Borch-Madsen ${ }^{11}$ described such injury in a 17-yearold boy who stumbled and fell onto a landing while walking down stairs. Ogden et al. ${ }^{12}$ reported simultaneous Watson-Jones type III fractures in a 14-yearold boy competing in a 40-yard dash. Maekawa et al. ${ }^{13}$ reported a 15 -year-old boy who pushed-off on both feet in doing a somersault, sustaining simultaneous Watson-Jones type III fractures. We believe that our report is the first case of simultaneous bilateral avulsion fractures of the proximal tibial epiphysis.

This type of fracture appears to heal well after closed reduction where the knee is extended by putting strong pressure over the tibial tubercle. Plaster cast immobilization in extension of the knee is continued for 4-8 weeks, depending on the adequacy and stability of the reduction. All incidents of this type of fracture occurred in older adolescents from 15 to 18 years of age, with the exception of Silberman's one case of a 12-year-old boy. Although two cases in our series showed epiphyseal closure on follow-up radiographs, no angular deformity or leg length discrepancy occurred because the patients were close to skeletal maturity. Vascular impairment is the most serious complication of this injury. A hyperextension injury that results in posterior displacement of the shaft or a direct crushing force may cause vascular compromise. However, an avulsion injury of the 
proximal tibial epiphysis may have less potential to damage the popliteal vessels because the periosteum on the posterior surface of the tibia remains intact and protects the popliteal vessels.

\section{References}

1 Silberman WW, Murphy JL. Avulsion fracture of the proximal tibial epiphysis. J Trauma 1966; 6: 592-4.

2 Usui M, Ando $\mathrm{H}$, Tangiku T. Three cases of avulsion fracture of the proximal tibial epiphysis in sports activities. Chubuseisaishi (Cent Jpn J Orthop Traumat) 1983; 26: 2167.

3 Ryu RKN, Debenham JO. An unusual avulsion fracture of the proximal tibial epiphysis. Clin Orthop 1985; 194: 181-4.

4 Salter RB, Harris WR. Injuries involving the epiphyseal plate. J Bone Joint Surg [Am] 1963; 45-A: 587-622.

5 Peterson CA, Peterson HA. Analysis of the incidence of injuries to the epiphyseal growth plate. J Trauma 1972; 12: 275-81.

6 Shelton WR, Canale ST. Fractures of the tibia through the proximal tibial epiphyseal cartilage. J Bone Joint Surg [Am] 1979; 61-A: 167-73.

7 Wilson JN. Injuries of the knee, Watson-Jones Fractures and Joint Injuries, 5th edn, vol. 2. Edinburgh: Churchill Livingstone, 1976: 1047-50.

8 Burkhart SS, Peterson HA. Fractures of the proximal tibial epiphysis. J Bone Joint Surg [Am] 1979; 61-A: 996-1002.

9 Levi JH, Coleman CR. Fracture of the tibial tubercle. Am J Sports Med 1976; 4: 254-63.

10 Christie MJ, Dvonch VM. Tibial tuberosity avulsion fracture in adolescents. J Pediatr Orthop 1981; 1: 391-4.

11 Borch-Madsen P. On symmetrical bilateral fractures of the tuberositas tibiae and ementia intercondyloidea. Acta Orthop Scand 1954; 24: 44-9.

12 Ogden JA, Tross RB, Murphy MJ. Fractures of the tibial tuberosity in adolescents. J Bone Joint Surg [Am] 1980; 62-A: 205-15.

13 Maekawa M, Kobayashi A, Tokunaga J, Fukumoto K, Ueno $\mathrm{H}$, Ohno K. Symmetrical bilateral fracture of the tibial tuberosity. Rinsho Seikei Geka (Clin Orthop Surg) 1981; 15: 195-7. 